\title{
Outcomes associated with lidocaine and amiodarone administration in pediatric in-hospital cardiac arrest
}

\author{
Jaroslaw Meyer-Szary ${ }^{1} \oplus$, Aleksandra Gasecka² $\odot$, Ivo John², Milosz J. Jaguszewski ${ }^{3}$, \\ Frank W. Peacock ${ }^{4}$, Natasza Gilis-Malinowska ${ }^{3} \odot$, Lukasz Szarpak ${ }^{5,6}$ \\ ${ }^{1}$ Department of Pediatric Cardiology and Congenital Heart Diseases, Medical University of Gdansk, Poland \\ ${ }^{2} 1^{\text {st }}$ Chair and Department of Cardiology, Medical University of Warsaw, Poland \\ ${ }^{3} 1^{\text {st }}$ Department of Cardiology, Medical University of Gdansk, Poland \\ ${ }^{4}$ Henry JN Taub Department of Emergency Medicine, Baylor College of Medicine, Houston, United States \\ ${ }^{5}$ Maria Sklodowska-Curie Medical Academy in Warsaw, Poland \\ ${ }^{6}$ Maria Sklodowska-Curie Bialystok Oncology Center, Bialystok, Poland
}

\section{This paper was guest edited by Prof. Togay Evrin}

Pediatric in-hospital cardiac arrest is a devastating condition with the average annual incidence of 15,200 cases in the United States [1]. The survival rate after hospital discharge remains poor $(\sim 55 \%)$ [2], although it shows an increasing trend in the last decade [3]. In the pediatric population, around $10 \%$ of patients have initial shockable rhythms (ventricular fibrillation or pulseless ventricular tachycardia) following cardiac arrest, and $15 \%$ of patients develop them during resuscitation. The rate of shockable rhythms varies depending on the patient age and is lowest for infants, followed by children and adolescents [4]. Early defibrillation and high-quality cardiopulmonary resuscitation are the core of treatment for cardiac arrests caused by shockable rhythms, followed by administration of adrenaline and antiarrhythmic drugs [5].

Amiodaron and lidocaine are used in the treatment of pediatric cardiac arrest with shockable rhythms refractory to defibrillation. Previously, amiodaron was recommended by the American Heart Association (AHA) Guidelines for Cardiopulmonary Resuscitation and Emergency Cardiovascular Care 2010: Pediatric Advanced Life Support [6], and by the European Resuscitation Council (ERC) 2010: Pediatric Life Support Guidelines [7] as the preferred antiarrhythmic. Currently, both AHA 2020 [8] and ERC 2021 Guidelines [5] state that amiodaron and lidocaine can be used interchangeably, depending on the physician's preferences. However, data regarding the outcomes associated with amiodarone and lidocaine administration in pediatric cardiac arrest are very limited. Therefore, this study is a systematic review and meta-analysis to determine the efficacy of amiodarone and lidocaine in pediatric cardiac arrest.

This present review and meta-analysis were performed following the Preferred Reporting Items for Systematic reviews and Meta-analysis (PRISMA) guidelines. The search of data included the Embase, Medline and the Cochrane from the databases' inception to April 15, 2021. Studies included in this meta-analysis met the following PICOS criteria: (1) Participants: patients $<18$ years of age with cardiac arrest due to any cause; (2) Intervention: amiodarone treatment; (3) Comparison: treatment with lidocaine; (4) Outcomes: detailed information for survival; (5) Study design: randomized controlled trials, observational trials comparing lidocaine and amiodarone in pediatric resuscitation. Studies were excluded if they were reviews, guidelines or articles not containing original data.

Address for correspondence: Jarosław Meyer-Szary, MD, PhD, Department of Pediatric Cardiology and Congenital Heart Diseases, Medical University of Gdansk, ul. M. Skłodowskiej-Curie 3a, 80-210 Gdańsk, Poland, tel: +48 5834928 82, e-mail: jmeyerszary@gumed.edu.pl 
Table 1. Pooled analysis of pediatric cardiac arrest outcomes in patients treated with lidocaine and amiodarone.

\begin{tabular}{|c|c|c|c|c|c|c|c|c|}
\hline \multirow[t]{2}{*}{$\begin{array}{l}\text { Adverse event } \\
\text { type }\end{array}$} & \multirow[t]{2}{*}{$\begin{array}{l}\text { No. of } \\
\text { studies }\end{array}$} & \multicolumn{2}{|c|}{$\begin{array}{l}\text { Events/ } \\
\text { /participants }\end{array}$} & \multicolumn{2}{|c|}{ Events } & \multicolumn{2}{|c|}{$\begin{array}{l}\text { Heterogeneity } \\
\text { between trials }\end{array}$} & \multirow{2}{*}{$\begin{array}{c}\text { P-value for } \\
\text { differences } \\
\text { across groups }\end{array}$} \\
\hline & & $\begin{array}{l}\text { Lidocaine } \\
\text { group }\end{array}$ & $\begin{array}{l}\text { Amiodarone } \\
\text { group }\end{array}$ & OR & $95 \% \mathrm{Cl}$ & P-value & I $^{2}$ statistic & \\
\hline \multicolumn{9}{|l|}{ Full cohort data } \\
\hline ROSC & 2 & $\begin{array}{l}307 / 430 \\
(71.4 \%)\end{array}$ & $\begin{array}{l}140 / 237 \\
(59.1 \%)\end{array}$ & 1.96 & $1.39-2.77$ & 0.45 & $0 \%$ & $<0.001$ \\
\hline Survival to $24 \mathrm{~h}$ & 2 & $\begin{array}{l}232 / 430 \\
(54.0 \%)\end{array}$ & $\begin{array}{l}94 / 237 \\
(39.7 \%)\end{array}$ & 1.94 & $1.39-2.69$ & 0.82 & $0 \%$ & $<0.001$ \\
\hline SHD & 2 & $\begin{array}{l}138 / 429 \\
(32.2 \%)\end{array}$ & $\begin{array}{l}55 / 235 \\
(23.4 \%)\end{array}$ & 1.68 & $1.16-2.44$ & 0.99 & $0 \%$ & 0.006 \\
\hline $\begin{array}{l}\text { SHD with favorable } \\
\text { neurological outcome }\end{array}$ & 1 & $\begin{array}{l}39 / 186 \\
(21.0 \%)\end{array}$ & $\begin{array}{l}30 / 141 \\
(21.3 \%)\end{array}$ & 0.98 & $0.57-1.68$ & NA & NA & 0.95 \\
\hline \multicolumn{9}{|l|}{ Matched cohort data } \\
\hline ROSC & 2 & $\begin{array}{l}203 / 303 \\
(67.0 \%)\end{array}$ & $\begin{array}{l}107 / 179 \\
(59.8 \%)\end{array}$ & 1.51 & $0.64-3.55$ & 0.04 & $76 \%$ & 0.35 \\
\hline Survival to $24 \mathrm{~h}$ & 2 & $\begin{array}{l}145 / 303 \\
(47.9 \%)\end{array}$ & $\begin{array}{c}71 / 179 \\
(39.7 \%)\end{array}$ & 1.48 & $0.77-2.83$ & 0.10 & $64 \%$ & 0.24 \\
\hline SHD & 2 & $\begin{array}{l}82 / 302 \\
(27.2 \%)\end{array}$ & $\begin{array}{l}43 / 179 \\
(24.0 \%)\end{array}$ & 1.31 & $0.84-2.05$ & 0.27 & $16 \%$ & 0.23 \\
\hline $\begin{array}{l}\text { SHD with favorable } \\
\text { neurological outcome }\end{array}$ & 1 & $\begin{array}{c}12 / 78 \\
(15.4 \%)\end{array}$ & $\begin{array}{c}20 / 85 \\
(23.5 \%)\end{array}$ & 0.59 & $0.27-1.31$ & NA & NA & 0.19 \\
\hline
\end{tabular}

$\mathrm{Cl}$ - confidence interval; NA — not applicable, OR — odds ratio; ROSC — return of spontaneous circulation; SHD - survival to hospital discharge

Following identification and selection of the relevant studies for the present meta-analysis and removal of duplicates and nonrelevant trials, two studies were included in the analysis $[9,10]$. Both studies focused on in-hospital cardiac arrest (IHCA).

Results of the pooled analysis of IHCA outcomes is presented in Table 1 . In the full cohort, the use of lidocaine in pediatric resuscitation was associated with a higher incidence of return of spontaneous circulation $(71.4 \%$ vs. $59.1 \%$, respectively; odds ratio [OR] 1.96; 95\% confidence interval [CI] 1.39-2.77; $\mathrm{p}<0.001$ ), survival to $24 \mathrm{~h}$ (54.0\% vs. $39.7 \%$; OR 1.94 ; $95 \%$ CI $1.39-2.69$; $\mathrm{p}<0.001)$ and survival to hospital discharge (32.2\% vs. $23.4 \%$; OR 1.68 ; $95 \%$ CI $1.16-2.44$; $\mathrm{p}=0.006$ ), compared to amiodaron. There were no differences regarding favorable neurological outcome at hospital discharge in patients who received lidocaine and amiodarone (21.0\% vs. $21.3 \%$, respectively; OR 0.98 ; 95\% CI 0.57-1.68; $\mathrm{p}=$ $=0.95)$. In the propensity-score matched cohort data (comparison of propensity-matched patients from the first study [9] and all patients from the second study [10], no significant differences between the use of lidocaine and amiodarone were found in terms of all researched outcomes.

In conclusion, despite better IHCA outcomes associated with lidocaine in the full cohort analysis, analysis of the propensity-matched data showed no significant differences between the treatment arms. Although the small number of studies included in this meta-analysis and lack of access to individual patient data is a limitation, the meta-analysis herein, implies that results of previous studies comparing lidocaine and amiodarone in pediatric cardiac arrest should be interpreted which caution, as the observed differences might be due to substantial differences in patient baseline and clinical characteristics. Further randomized controlled trials are warranted to establish which treatment strategy is associated with better outcomes.

\section{Conflict of interest: None declared}

\section{References}

1. Holmberg MJ, Ross CE, Fitzmaurice GM, et al. Annual incidence of adult and pediatric in-hospital cardiac arrest in the united 
states. Circ Cardiovasc Qual Outcomes. 2019; 12(7): e005580, indexed in Pubmed: 31545574.

2. Holmberg MJ, Wiberg S, Ross CE, et al. Trends in survival after pediatric in-hospital cardiac arrest in the United States. Circulation. 2019; 140(17): 1398-1408, doi: 10.1161/CIRCULATIONAHA.119.041667, indexed in Pubmed: 31542952.

3. Shimoda-Sakano TM, Schvartsman C, Reis AG. Epidemiology of pediatric cardiopulmonary resuscitation. J Pediatr (Rio J). 2020; 96(4): 409-421, doi: 10.1016/j.jped.2019.08.004, indexed in Pubmed: 31580845 .

4. Samson RA, Nadkarni VM, Meaney PA, et al. American Heart Association National Registry of CPR Investigators. Outcomes of in-hospital ventricular fibrillation in children. N Engl J Med. 2006; 354(22): 2328-2339, doi: 10.1056/NEJMoa052917, indexed in Pubmed: 16738269.

5. Van de Voorde P, Turner NM, Djakow J, et al. European Resuscitation Council Guidelines 2021: Paediatric Life Support. Resuscitation. 2021; 161: 327-387, doi: 10.1016/j.resuscitation.2021.02.015, indexed in Pubmed: 33773830.

6. Kleinman ME, Chameides L, Schexnayder SM, et al. Part 14: pediatric advanced life support: 2010 American Heart Association Guidelines for Cardiopulmonary Resuscitation and Emergency Cardiovascular Care. Circulation. 2010; 122(18 Suppl 3):
S876-S908, doi: 10.1161/CIRCULATIONAHA.110.971101, indexed in Pubmed: 20956230.

7. Biarent D, Bingham R, Eich C, et al. European Resuscitation Council Guidelines for Resuscitation 2010 Section 6. Paediatric life support. Resuscitation. 2010; 81(10): 1364-1388, doi: 10.1016/j.resuscitation.2010.08.012, indexed in Pubmed: 20956047.

8. Topjian AA, Raymond TT, Atkins D, et al. Pediatric Basic and Advanced Life Support Collaborators. Part 4: Pediatric Basic and Advanced Life Support 2020 American Heart Association Guidelines for Cardiopulmonary Resuscitation and Emergency Cardiovascular Care. Pediatrics. 2021; 147(Suppl 1), doi: 10.1542/ peds.2020-038505D, indexed in Pubmed: 33087552.

9. Holmberg MJ, Ross CE, Atkins DL, et al. Lidocaine versus amiodarone for pediatric in-hospital cardiac arrest: An observational study. Resuscitation. 2020; 149: 191-201, doi: 10.1016/j.resuscitation.2019.12.033, indexed in Pubmed: 31954741.

10. Valdes SO, Donoghue AJ, Hoyme DB, et al. Outcomes associated with amiodarone and lidocaine in the treatment of in-hospital pediatric cardiac arrest with pulseless ventricular tachycardia or ventricular fibrillation. Resuscitation. 2014; 85(3): 381-386, doi: 10.1016/j.resuscitation.2013.12.008, indexed in Pubmed: 24361455. 